\title{
Dependence of Color of Clupak Paper Produced on Bleaching Level of Pulp Fiber
}

\author{
Husejin Duraković \\ Department of Paper Production, Pulp and Paper Production Company, Bosnia and Herzegovina
}

Copyright $\subseteq 2019$ by authors, all rights reserved. Authors agree that this article remains permanently open access under the terms of the Creative Commons Attribution License 4.0 International License

\begin{abstract}
This research work deals with modification of the color of paper in commercial clupak dynamic image registration. According to the standard technology of production of kraft pulp, from which the production clupak paper, the paper obtained is dark brown in color. Market demand is based on quality and price of the product. Step further in these demands is demand for certain balanced and brighter shade of color of sack kraft paper. Lately it is demanded from our company to produce sack kraft paper with lighter shade of color. This problem can be solved in two ways: by coloring pulp fiber and by bleaching it. Methods of production of sack kraft paper with lighter shade, as well as results achieved, will be presented in this document.
\end{abstract}

Keywords Clupak Paper, Coloring, Bleaching

\section{Introduction}

The production of clupak paper is a very complex process. To produce this paper many conditions must be met, from wood selection, chip preparation, cellulose production with a certain kappa number, to preparation and fiber treatment, all in order to produce paper of a certain shade $e^{1,2,3,4}$.

One of the most important steps in high porosity clupak paper production is the cellulose fiber treatment. The preparation consists of several operations like densifying, milling, cleaning, adding certain chemical compounds, forming of the paper sheet on the paper machine wire.

The effects of the raw resources, chemical compounds and treatment on the clupak paper shade are different ${ }^{5}$. This work presents a method with which to produce a brighter shaded clupak paper keeping in mind all the influencing elements ${ }^{6}$.

\section{Preparation of Wood and Cellulose Fibers}

Cellulose production for brighter shaded clupak paper is performed using softwood, $60 \%$ fir (spruce), $30 \%$ and $10 \%$ sawmill waste. This ratio is important because of the fiber length of these wood types ${ }^{7}$. The following table presents the fiber length and width of softwood trees.

Table 1. Fiber Length of Various Softwood Trees

\begin{tabular}{|c|c|c|c|}
\hline Nr & TYPE & $\begin{array}{c}\text { FIBER LENGTH } \\
{[\mathbf{m m}]}\end{array}$ & $\begin{array}{c}\text { FIBER WIDTH } \\
{[\mathbf{m m}]}\end{array}$ \\
\hline 1. & Fir & $2,6-4,4$ & $0,030-0,075$ \\
\hline 2. & Pine & $2,6-4,4$ & $0,030-0,075$ \\
\hline 3. & Spruce & $2,4-3,8$ & $0,025-0,070$ \\
\hline
\end{tabular}

During the wood selection for clupak paper it is very important to preserve the ratio between pine and fir/spruce.
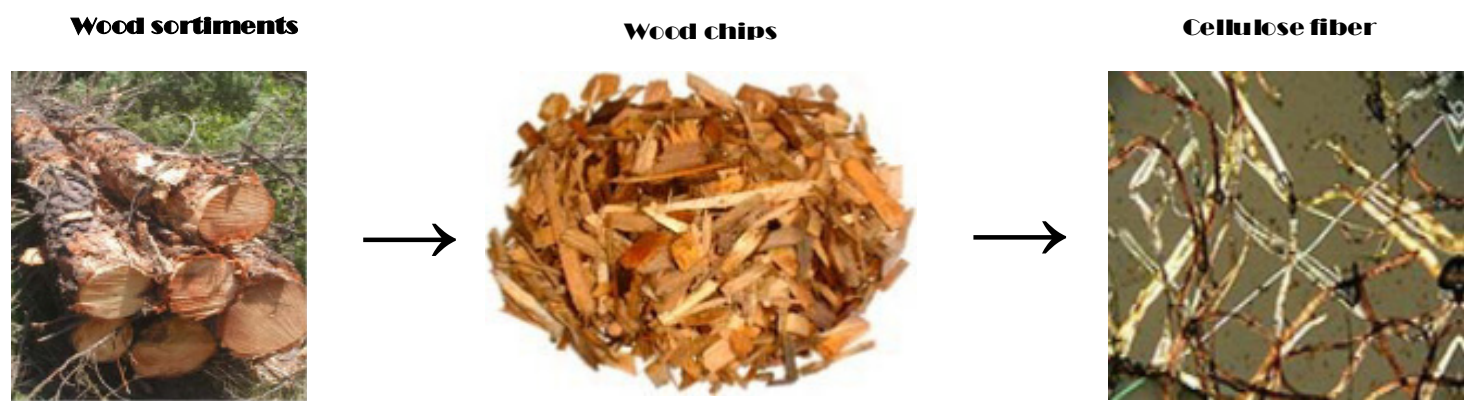

Figure 1. The method of preparing cellulose fibers from wood assortments 
Cellulose is a homopolysaccharide, consisting of a large number $(300-15000)$ of glucose units which are bonded to each other by $\beta(1,4)$ glucoside bonds. Cellulose molecules are linear ${ }^{8}$. Cellulose is insoluble in water and organic solvents, it has a low reaction value and a great mechanical resistance. It is useless for humans as a food source because humans don't have the necessary enzymes to break down the cellulose down to glucose.

Regarding industrial scale use, cellulose is obtained from various resources of vegetation origin. Most commonly it is obtained from trees, softwood (pine, fir, spruce) and hardwood (beech, poplar, maple, birch). For a long time now, even hardy annual plants are used such as grass, straw and reed. Cellulose production includes tree or other resource chipping, which is achieved with special devices.

During the chemical treatment of chopped raw resource degradation and dissolution of lignin, hemicellulose and other compounds occurs, while cellulose remains undissolved at various levels of purity. Lignin is soluble in hot solutions of alkaline hydroxides and acid solutions of alkalis and alkaline bisulfite, while hemicellulose dissolves in diluted acids and alkalis on room temperature? Depending on the resource type and desired cellulose quality, two industrial methods are applied: alkaline (sulphate) and acid (bisulfite).

\section{Eksperimental Part}

In order to determine the various effects of kappa on the paper shade, it is necessary to perform an experiment. The experiment includes laboratory tests of cellulose fiber being dyed with various inks, as well as an industrial test.

\subsection{Kappa Value Determination Methods}

The kappa value is an indicator of lignin content (hardness) of the cellulose fiber. There is no standard ratio between the Kappa value and lignin content in the fiber ${ }^{10}$. This ratio changes in dependence of the wood type and delignification process. If the Kappa value is used to express the lignin content index in the cellulose fiber, then a particular ratio must be used for every type of fiber.

\subsubsection{Sampling and Sample Preparation}

The cellulose samples are taken from reels according to the ISO 7213:1981 standard. The initial sample is dried on air and then chopped to smaller pieces, 3 to 10 grams. Before the measurements, the sample is kept near the scale at natural conditions for at least 20 minutes. Raw unsorted samples are taken by the Kamyr crew, at the position C-49. The Kamyr samples are transported by the PHL/Laborant I/Laborant II. After the sorting process, a cellulose fiber sheet is created on the BlatBinder machine. The sheet is then dried up to absolute dryness.

\subsubsection{Operation Method}

It is necessary to measure (with a $0,001 \mathrm{~g}$ accuracy) the amount of cellulose fiber which will spend nearly $50 \%$ $(\mathrm{m} / \mathrm{m})$ of a potassium-permanganate solution. The potassium-permanganate solution usage must be between $30 \%$ and $70 \%(\mathrm{~m} / \mathrm{m})$. Simultaneously, another sample is prepared according to the ISO 638:1978 standards method, which is used to determine the amount of dry matter. The sample is decomposed in $500 \mathrm{ml}$ of distilled water until the lumps and broad fibers are broken apart. During the decomposition it is important to make sure that the fiber is not damaged ${ }^{11}$. The decomposed sample is transferred into a $1500 \mathrm{ml}$ glass or disintegrator, and rinsed with water so that the final volume is $790 \mathrm{ml}$. The glass is placed in a water bath which maintains a steady temperature of $25,0+$ $0,2{ }^{\circ} \mathrm{C}$. The mixer is adjusted to create a vortex $25 \mathrm{~mm}$ deep. A $250 \mathrm{ml}$ laboratory glass is filled with $100,0+0,1$ $\mathrm{ml}$ of potassium-permanganate solution and $100 \mathrm{ml}$ of sulphuric acid. The solution temperature is set to $25^{\circ} \mathrm{C}$ and the sample is added quickly, while the time is measured ${ }^{12}$. The glass is rinsed with at least $10 \mathrm{ml}$ of distilled water which is added into the reacting solution. The total volume must be $1000 \mathrm{ml}$. After exactly 10 minutes, the reaction is stopped by adding $20 \mathrm{ml}$ of potassium-iodide solution. Immediately after the mixing, but without filtration, the free iodide is titrated using sodium-thiosulphate. At the end of the titration a few drops of starch are added ${ }^{13}$.

\subsubsection{Calculation and Presentation of the Results}

\section{Result Calculation}

Kappa - number x. Presented as a number value with no unit, calculated from:

$$
\mathrm{V}_{1}=\frac{\left(V_{2}-V_{3}\right) c}{0,02 \times 5} ; \quad \mathrm{X}=\frac{V_{1} d}{M}
$$

Representing;

$\mathrm{V}_{1}$ - potassium-permanganate solution volume (t.4.3) spent for analysis in milliliters;

$\mathrm{V}_{2}$ - sodium-thiosulphate solution volume (t.4.4) spent for the referent analysis in milliliters;

$\mathrm{V}_{3}$ - sodium-thiosulphate solution volume (t.4.4) spent for analysis in milliliters;

$\mathrm{c}$ - sodium-thiosulphate solution concentration (t.4.4) in moles per liter, $(0,02 \mathrm{~mol} / \mathrm{l})$;

$\mathrm{d}$ - correction factor for usage of $50 \%(\mathrm{~m} / \mathrm{m})$ of permanganate. $d$ depends on the value of $V_{1}$;

$\mathrm{m}$ - sample mass after drying, in grams.

\section{Result Presentation}

The Kappa number of cellulose is expressed as an arithmetic average value of two experiments with the following accuracy:

Kappa number $\leq 50$, to the first 0,1 value;

$50<$ Kappa number $\leq 100$, to the first 0,5 value; 
Kappa number $>100$, with no decimals.

\subsubsection{Reporting}

The obtained results are communicated to the production unit, by phone or in written form, by the laboratory operator I/II or the cellulose laboratory operator. An analysis report from a non-scheduled sample must contain the following information:

a/ standard marking ISO 302-1981 (E) ; (SCAN-C 1:00 ; JUS H.N8.180) to signify that this method is in correspondence with the standard, or a statement if it is internal

$\mathrm{b} /$ all the information necessary to identify the sample (name, date, position of sampling)

$\mathrm{c} /$ number of tests, if it is higher than 1

$\mathrm{d} /$ type of method, if a different one is used

e/ results, expressed as a numerical value

f/ observations, noticed during testing

$\mathrm{g} /$ procedures which are not stated in the used method, but which could affect the results

\subsection{Coloring of Cellulose Fibers during Clupak Paper Production}

In order to obtain the information, in which amount a certain shade of ink should be used during the coloring process of cellulose fiber production, it is necessary to perform various tastings using various inks.

During the laboratory trial of paper coloring, the following inks were used: 0,30 \% Astra braun Y; 0,03\% Astra braun RL and 0,06\% Levacell braun 6R.

The trial was performed under laboratory conditions using multiple samples with different amounts of inks, which were compared to the referent sample. The process consisted of taking a standard sample of cellulose fibers, to which ink is added and homogenized as usually after which a standard sheet is prepared. The dried sheet can then be compared to sheets which have not been colored or with sample sheets from customers.

\subsection{The Bleaching of Cellulose Fibers during Clupak Paper Production}

This method is based on the reductive Boron bleaching. The reductive Boron bleaching technology includes adding the two chemical agents directly into the mass flow pipes:
A/ Sodium Bisulfite (NsHSO3) and B/ BORINO
BORINO is an alkaline sodium borohydride solution of
- $\mathrm{NaBH} 4=12 \%$
- $\mathrm{NaOH}=40 \%$ and
- Water to balance the system
BORINO Bleaching Reaction

This is a multiple bleaching reaction with 3 reduction agents for bleaching:

Bleaching and color removal:

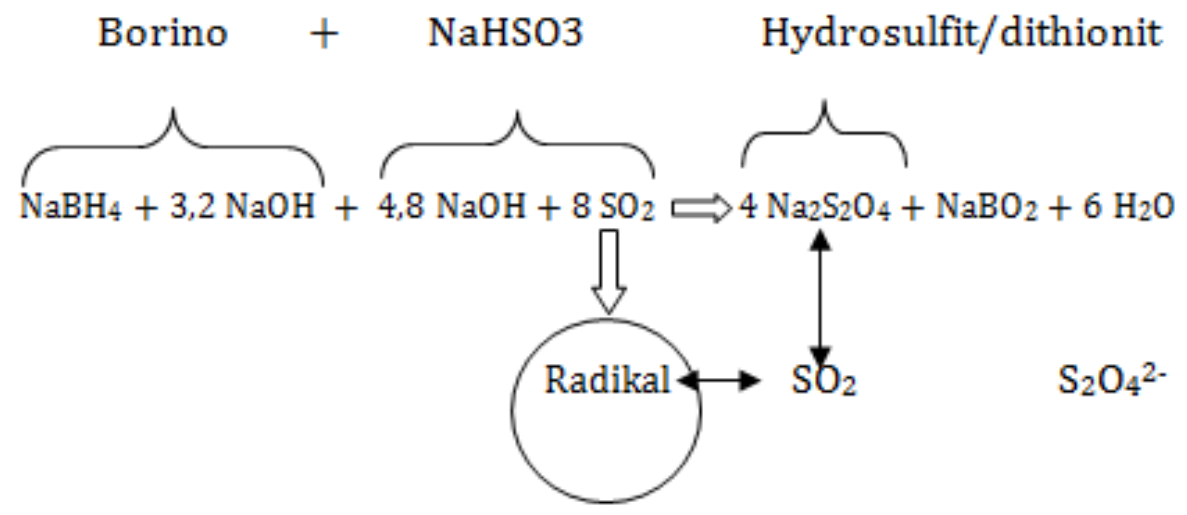


The reaction is very quick

\section{Reductive Boron Bleaching}

This bleaching portrays the synergic effect of the 3 reduction agents which affect the cellulose mass by bleaching and color removal, they are:

Sodium bisulfite

- Weak reduction agent,

- Acts as a oxygen cleaner,

- Acidifies the cellulose pulp,

- Reduces the leftover peroxide,

- Cause preliminary bleaching and coulour removal.

Sodium Borohydride

- A strong reduction agent,

- Reduces the sodium bisulphite and hydrosulphite on the wire section.

Sodium Hydrosulphite (Produced on the Wire Section)

- Moderate reduction agent,

- Stabilizes the colour removal,

- Brightens the cellulose mass.

Agents Dosage:

Typical Dosage

- Borino $1-3 \mathrm{~kg} / \mathrm{ton}$ (of the product)

- Sodium bisulphite $8-24 \mathrm{~kg} / \mathrm{ton}$ (as $40 \%$ product)

Dosage Position:

- Into the cellulose flow (before P-6).

Cellulose mass Condition during Dosage:

- Cellulose mass consistency $3-4 \%$,

- Reaction time 30-40 min,

- Cellulose mass temperature $55-65^{\circ} \mathrm{C}$ (better performances at higher temperatures),

- $\quad \mathrm{pH}$ range of $5-8$.

Brightness increase of about $3-4 \%$ ISO units for 2 $\mathrm{kg} / \mathrm{ton}$ of Borino agent.

The image 5.25. shows the dosing positions of the agents.

The agents' names and dosing amounts are presented in the next table.
Table 2. Agents and norms for paper bleaching

\begin{tabular}{|c|c|c|c|}
\hline Nr & AGENT NAME & $\begin{array}{c}\text { DOSING } \\
\text { POSITION }\end{array}$ & $\begin{array}{c}\text { NORM } \\
{[\mathbf{k g} / \mathbf{t p}]}\end{array}$ \\
\hline 1. & $\begin{array}{c}\text { ChemBoron } \\
\text { (Sodium Borohydride } \\
\text { NaBH }_{4} \text {, solution) }\end{array}$ & $\begin{array}{c}\text { Before pump P-6 } \\
\text { (after the LC } \\
\text { refining) }\end{array}$ & 0,95 \\
\hline 2. & $\begin{array}{c}\text { Sodium bisulfite } \\
\text { solution }\end{array}$ & & 6,80 \\
\hline
\end{tabular}

\section{Results of Research}

Research has been planned and implemented in response to customer demands for the Lighter clapper paper used for bag production. The customer's remark was that it was our knitted paper is darker than the one offered by the competition. They were looking for that paper paint with color or bleach with chemicals. The coloring is done laboratory and not gave the desired effect. After that, whitening of the pulp on a paper machine approached chemicals. Following the laboratory and industrial research, the following results were achieved.

\subsection{Kappa Value and Its Influence on the Color of the Produced Paper}

The kappa number is an indicator of lignin content (hardness) or cellulose whiteness. There is no common correlation between the kappa number and lignin content in the cellulose. This ratio changes depending on the wood type and delignification method. If the kappa number is used to describe the content index of lignin in the cellulose, then a special ratio is given for every cellulose type.

The influence of the kappa number on the cellulose shade (brightness) is shown in the next table.

Table 3. Paper brightness in correlation to kappa number

\begin{tabular}{|c|c|c|}
\hline $\mathrm{Nr}$ & Kappa number & Brightness \\
\hline 1 & 33,5 & 58,43 \\
\hline 2 & 39,3 & 57,50 \\
\hline 3 & 40,8 & 56,68 \\
\hline 4 & 43,1 & 53,67 \\
\hline 5 & 45,9 & 53,00 \\
\hline 6 & 47,3 & 52,50 \\
\hline
\end{tabular}

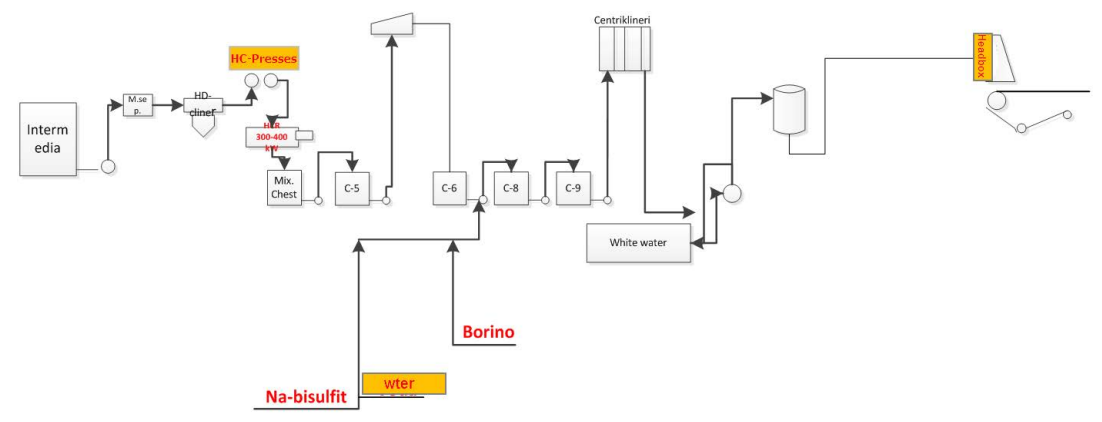

Figure 2. Schematic view of the dosing positi 


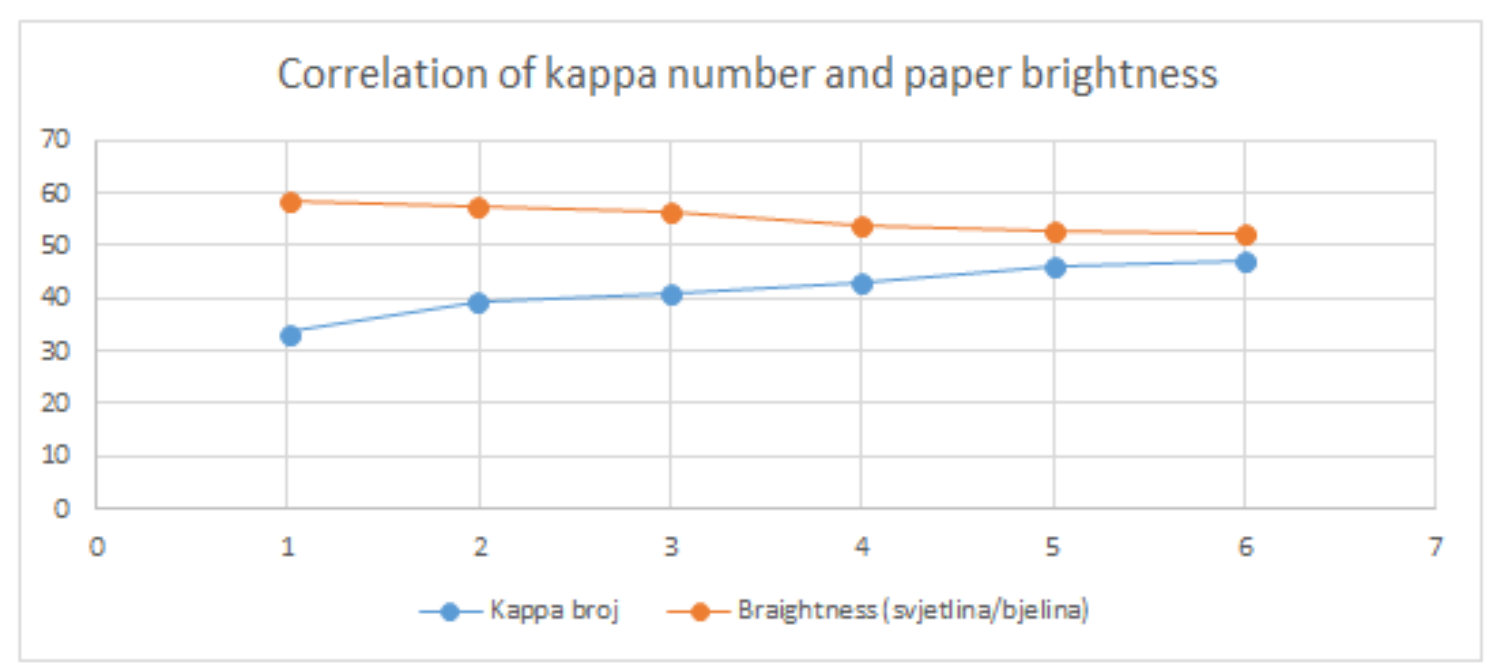

Figure 3. Chart of kappa number and cellulose brightness correlation

From the previous table and the picture it is visible that the increase in the number of caps decreases the brightness of the paper and vice versa. The reason is that with the larger cap of the number of cellulose the content of the undivided lignin is higher, which gives the darker shade of cellulose fiber and paper.

\subsection{Shades of Clupak Paper Obtained through Cellulose Fiber Coloring}

During the experimental coloring of paper in a laboratory, the following colors were used: $0,30 \%$ Astra braun Y; 0,03\% Astra braun $\mathrm{Y}$ and $0,06 \%$ Levacell braun 6R. The experimentally achieved colors are shown in the next images.
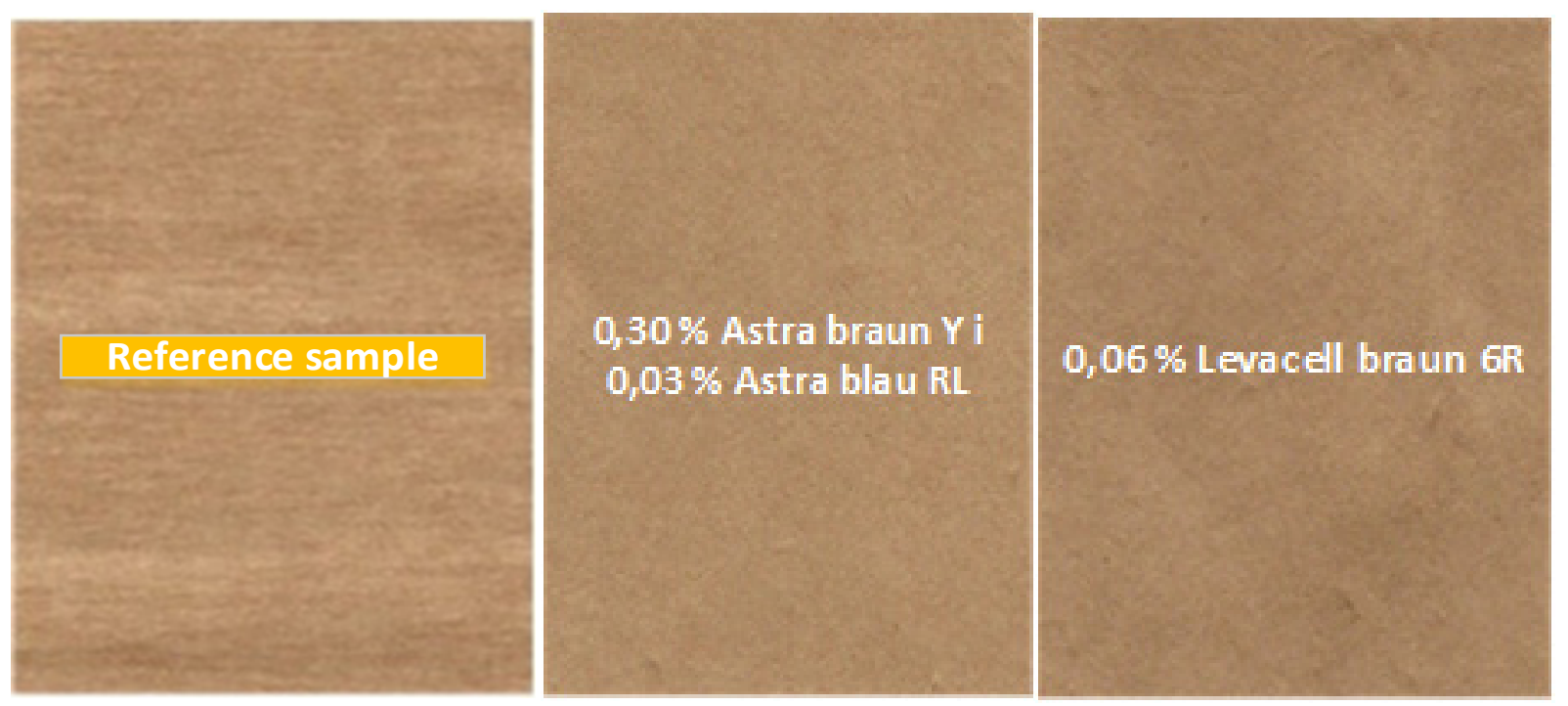

Figure 4. Reference and Colored Paper Samples

Analyzing the color shades of paper obtained by coloring different types of colors, we found that none of the obtained paper shades were what customers expect, and it was necessary to access the bleaching test of cellulose fibers.

\subsection{Shades of Clupak Paper Obtained through Cellulose Fiber Bleaching}

During the cellulose fiber bleaching two agents were used, Boron and Sodium bisulfite. The research began by taking a paper sample of unbleached cellulose, as the reference sample. Multiple samples were produced, with a wide range of agents amounts added to the cellulose. The resulting shade are shown in the next image. 

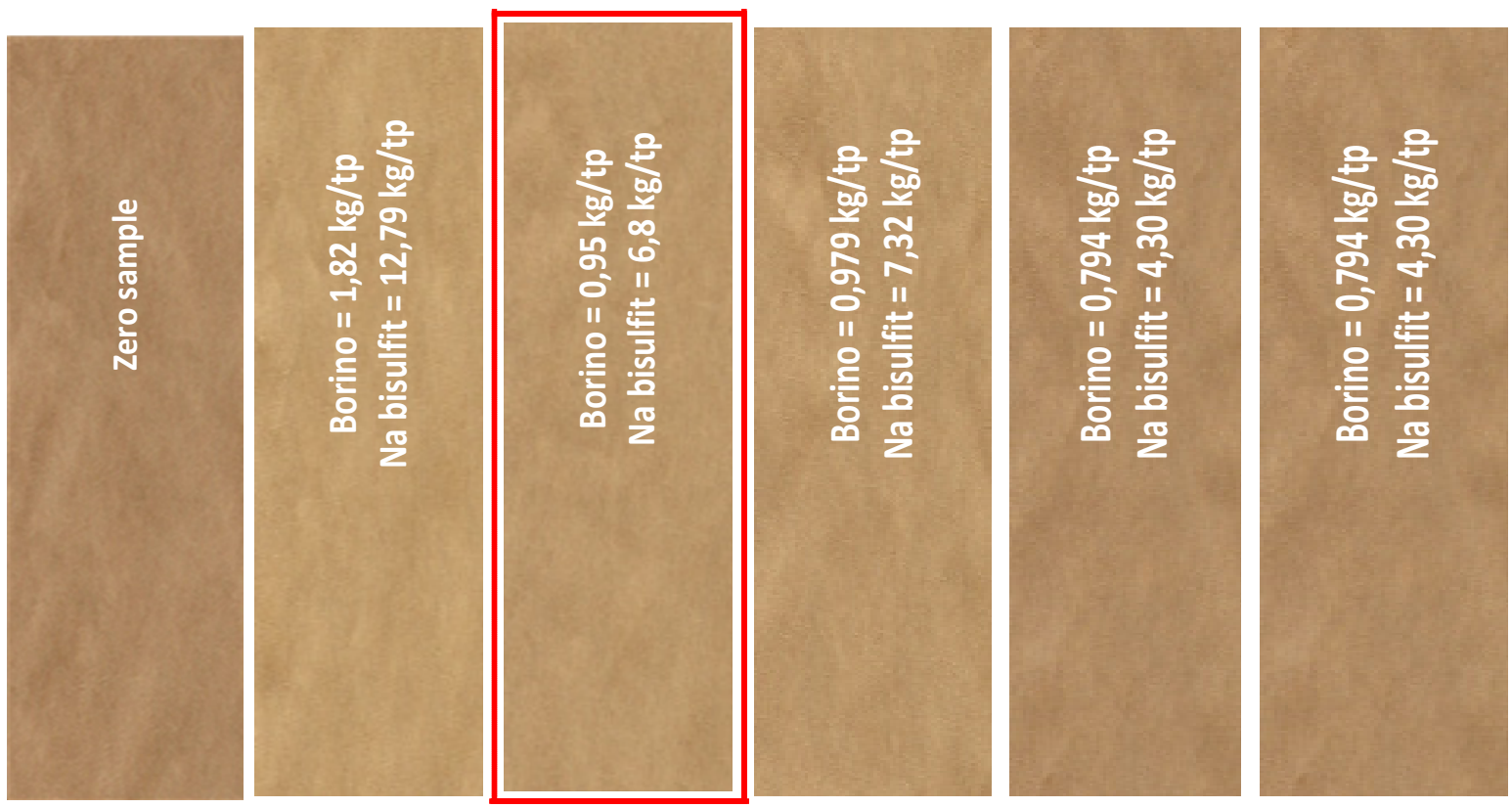

Figure 5. Paper Shade Samples from Industrial Production

Analyzing the obtained color shades obtained by bleaching different amounts of chemicals, we found that a large number of paper tones were compared to customer requirements, and it was found that customers' requirements could be met and produced paper of the listed characteristics.

\section{Conclusions}

After analysis of the laboratory and industrial trials, we can reach the following conclusions,

1. After analyzing the relation between Kappa number of the cellulose fiber and clupak paper shade, we can conclude that a higher Kappa number causes a darker produced clupak paper,

2. By coloring the cellulose fiber with different types of inks, very dark and non-uniform paper shades have been achieved, which is not acceptable since the market trends shift towards lighter paper,

3. By cellulose fiber bleaching using chemicals such as boron and bisulfite, various different paper shades have been achieved which can be presented to customers in order for them to make a decision, which fits them best

4. The performed experiments indicate that the costs of coloring and bleaching cellulose fibers can be high and reach 10 to $15 € / \mathrm{tp}$, which can potentially cause problems during sales.

\section{REFERENCES}

[1] Technical manual from Kemira, Austria,

[2] Duraković H., „Proizvodnja clupak papira“, Planjax Tešanja 2010.godine,

[3] PM-4 Technical documentation, Natron-Hayat, SANO Japan
[4] Industrial research planning for the clupak paper production process optimization, (2014).

[5] Andrews, D. H. and Singh, R. P. (1979) Peroxide Bleaching. In The Bleaching of Pulp, 3rd Edh., (R. P. Singh, ed.) Atlanta, GA: Tappi Press,

[6] Sjöström, E. (1981) Wood Chemistry: Fundamentals and Applications New York, London: Academic Press, pp. 146-168.

[7] Valko, E. I. (1955) Bleaching. In Chemistry and Chemical Technology of Cotton (K. Ward, ed.) New York: Interscience Publishers, pp. 117-215.

[8] Jump up ^ "Pulp bleaching chemicals information from PQ Corp". Archived from the original on April 2, 2007. Retrieved 2007-09-17.

[9] Jump up ^ Sillanpää, Mervi (2005). "Studies on washing in kraft pulp bleaching" (Thesis; PDF). Faculty of Technology University of Oulu, Finland. Retrieved 2007-09-19.

[10] Jump up ^ Singh, R.P. (1979). The Bleaching of Pulp (3rd ed.). Atlanta: TAPPI Press.

[11] Jump up $\wedge$ Haugan, Marianne; Gregersen, Øyvind Weiby (2006). "Hydrogen peroxide bleaching of mechanical pulp fines". Nordic Pulp and Paper Research

[12] Bouchard, J.; Maine, C.; Berry, R.M.; Argyropoulos, D.S. (1996). "Kraft pulp bleaching using dimethyldioxirane: stability of the oxidants". Can. J. Chem. 74 (2): 232-237. Doi:10.1139/v96-026. Archived from the original on 2012-05-27. Retrieved 2007-09-20.

[13] Suss, H.U.; N.F. Nimmerfroh (1993). "Peroxide Bleaching Technology Review". Workshop on Emerging Pulping and Chlorine-free Bleaching Technologies. Raleigh, N.C. 